\title{
The Methodological Implications of the Schutz-Parsons Debate
}

\author{
Christian Etzrodt \\ Department of Basic Education, Akita International University, Akita, Japan \\ Email: etzrodtc@hotmail.com
}

Received November 19 $9^{\text {th }}$, 2012; revised December 20 $0^{\text {th }}$, 2012; accepted December $31^{\text {st }}$, 2012

\begin{abstract}
The aim of this paper is an analysis of the different standpoints of Parsons and Schutz concerning Weber's suggestion that sociological explanations have to include the subjective point of view of the actors, the Cartesian Dilemma that the actor's consciousness is not accessible to the researcher, and the Kantian Problem that theories are necessary in order to interpret sensory data, but that there is no guarantee that these theories are true. The comparison of Schutz's and Parsons's positions shows that Parsons's methodology is naïve and unsuitable for a sociological analysis. But although Schutz's methodological standpoint is much more reasonable, it is also problematic, because it excludes highly abstract social "facts" such as social systems from the research agenda. Parsons can deal with such highly abstract facts, despite the drawback that with his methodology the truth content of theories cannot be judged.
\end{abstract}

Keywords: Alfred Schutz; Talcott Parsons; Methodology; Interpretative Sociology; System Theory

\section{Introduction}

Around 1938, the editor of the British journal Economica, Friedrich August von Hayek, invited one of his former students, Alfred Schutz, to write a review of Talcott Parsons's The Structure of Social Action (1937). Schutz agreed, and the first meeting between Schutz and Parsons took place in 1939. Parsons along with Joseph Schumpeter invited Schutz to present a paper about rationality in the social world at the Harvard Faculty Club on April 13, 1940 (Barber, 2004: p. 91). However, their scientific correspondence did not start until November 1940, when Schutz sent Parsons the first version of his review of The Structure of Social Action. The correspondence ended in April 1941 after an uneasy discourse about methodology and action theory. Schutz and Parsons decided not to make their dispute public. Ultimately, the review was never published in Economica. Several years after the early death of Alfred Schutz, his wife Ilse Schutz and Talcott Parsons consented to publish the correspondence (Grathoff, 1978b: p. 17). This is the historical background of the Schutz-Parsons debate.

The Schutz-Parsons debate, although not really recognized as such, is for me one of the most important scientific debates in sociology. It handles questions that are still vital and largely unsolved (cf. Coser, 1979: p. 682; Tibbets, 1980: p. 357; Ho, 2008: p. 384). Every sociologist has to clarify his/her standpoint in relation to these questions. This debate deals with methodological principles that should be applied in sociology. What is the difference between the natural sciences and the social sciences, and should the methods of the natural sciences also be applied in the social sciences? Is there a unity of methods in sociology, or is the choice of the methods dependent on the research program? Is it possible to use the same methods in micro- as in macrosociology? This is, I think, a very interesting question, because we can find attempts to bridge the gap between micro- and macrosociology or agency and structure, but this is perhaps impossible from the methodological point of view.

I will discuss in this paper the different methodological standpoint of Schutz and Parsosn in relation to what Richard Grathoff called the Weberian Suggestion, the Cartesian Dilemma, and the Kantian Problem, and will conclude with a systematic summary of their positions.

\section{The Weberian Suggestion}

The first methodological point on which Alfred Schutz and Talcott Parsons had different opinions was called by Richard Grathoff the Weberian Suggestion. Max Weber's basic aim of his interpretative sociology was a methodological foundation of sociology that makes it possible to grasp the subjective motives and intentions of the actors. After defining several key sociological concepts, his work was mainly concerned with the historical analysis of social structures. Both Alfred Schutz and Talcott Parsons followed the Weberian Suggestion that a sociological theory must begin with the individual actor. But the ways they tried to provide this foundation of sociology differed in relation to their positions in the Methodenstreit in economics (cf. Grathoff, 1978b: p. 10).

The Methodenstreit in economics was mainly a debate between the leader of the Austrian School of Economics Carl Menger (1840-1921) and the leader of the German Historical School Gustav Schmoller (1838-1917). The debate started in 1883 after the publication of Menger's book on methodology, where he proposed an economic approach as a pure theory. Economics should be based, in his opinion, on general universal concepts of human action (which are a priori true) and antecedent conditions, and a deductive method. Schmoller on the other hand argued for an economic approach based on concrete historical facts, an inductive method, and a focus on the economy as a whole. He criticized Menger's approach for its unrealistic assumptions and its irrelevance to the real, existing economy, because of the high degree of abstractness of the general concepts, and their empirical emptiness, whereas Menger replied that historical facts can only be interpreted if the researchers already have a scheme of interpretation (Fusfeld, 1987: p. 454; Prendergast, 1986: p. 22; Etzrodt, 2004: p. 98). 
When Schutz studied economics and law in Vienna, the Methodenstreit was still alive. Schutz in his attempt to defend the methodological position of the Austrian School against the accusations of the German Historical School turned his attention to Max Weber, who had an intermediate position in the debate. Weber tried to describe historical processes by using generalized ideal types and emphasizing the importance of the subjective point of view of the actors (Prendergast, 1986: p. 1ff.). But although Weber accepted the position of the Austrian School that a general scheme of interpretation is necessary for the analysis of concrete historical facts, he avoided the mistaken belief of the Austrian economists that the general concepts have to be true a priori. He insisted instead that the construction of generalized ideal types depends on the researcher's value-standpoint and interests, and therefore is arbitrary. Schutz's methodological thinking was inspired by Max Weber's work. He accepted the methodological individualism of Max Weber and the Austrian School. He agreed with Weber that general concepts are not a priori true, but he also rejected Weber's conclusion that ideal types are entirely arbitrary. For Schutz, Weber arrived at a wrong conclusion in his analysis because he did not realize the problems related to the method of "understanding". Weber had failed to explain how an observer can understand the subjective meaning of the observed persons' actions (Grathoff, 1978a: p. 395). Schutz turned to Husserl's phenomenology for a more satisfactory formulation of a concept of understanding, based on the analysis of the stream of consciousness (Khairy, 1986: p. 131), in order to find an explanation of why people actually share ideal types. Finally these methodological considerations led Schutz to the question of how an action theory must be constructed in order to deal with the problem of intersubjective understanding. Schutz's main analysis became the (subjective and intersubjective) connection of motives and the structure of the life world in general terms.

In contrast to Alfred Schutz, methodology for Talcott Parsons was not a means, but rather a background problem, whose solution defined his research program. Parsons studied economics under teachers of different economic schools. At the Amherst College he was influenced by institutional economists Walton Hamilton and Clarence Ayres and in the London School of Economics by Edwin Cannan, who analyzed the capitalist system as a whole based on concrete historical descriptions of institutions similar to the German Historical School. Later at Harvard he came into contact with neoclassical economists like Frank W. Taussig, whose aim was to develop a pure theory in the sense of the Austrian School of Economics based on methodological individualism and on general universal concepts. Finally Parsons adopted the position of the biochemist Lawrence J. Henderson. Henderson emphasized in his lectures about Vilfredo Pareto the importance of the system and of general concepts. Parsons accepted general concepts as his main methodological tool, and his attempt to reconcile the fundamental discrepancy between the society as a whole (institutional economics) or the system (Henderson) on the one side, and the individual on the other (neoclassical economics), defined his research program (cf. Camic, 1991: pp. xxxii-xxxv). He took on the problem of constructing a social theory which could eliminate the fundamental conflict between individual and collective interests - the classical problem of Thomas Hobbes.

For a solution of this problem Parsons discussed four main social scientists: the two economists Alfred Marshall and
Vilfredo Pareto, and the two sociologists Émile Durkheim and Max Weber. He recognized that an economic explanation of the existence of social order based on the main assumption of selfish utility-maximizing behavior is impossible (Turner, 1994: p. 314). Parsons showed that Marshall's economic theory does not necessarily imply egoistic motives (Parsons, 1937: p. 162ff.). Pareto was interesting for Parsons, because he introduced nonlogical elements of human actions (Parsons, 1937: p. 185ff.) and the concept of the social system (Parsons, 1937: p. 219ff.). The next step toward a solution to the utilitarian dilemma was offered by Durkheim by deriving individual ends from social norms (Parsons, 1937: p. 464; cf. Zafirovski, 2006: p. 96f.). Finally, Parsons ended with Max Weber's multidimensional theory of motivation (Zafirovski, 2006: pp. 97-99) and his concept of value-rational action. Within this concept of value-rationality Parsons saw the solution to the Hobbes problem. In his voluntaristic theory he started with selfish utility-maximizing instrumental rational actors, but in contrast to economic theory, he added that these actors are not isolated. They are born into a society with an existing culture and value-system. In the socialization process these actors internalize the culture and values of this society, which then constrains the individual interests into culturally determined patterns or value-attitudes (Skidmore, 1975: p. 155f.; Parsons, 1951: p. 211). The result is that the actors want what they should want (Goode, 1960: p. 251). Or to put it in economic terms: Parsons's voluntaristic theory is based on selfish utility-maximizing actors, but their preferences are determined by the (unselfish) norms of the society.

[A]t no stage can we completely separate the individual from the society of which he is a part. The individual, in any really intelligible sense, does not exist apart from his relations with other individuals (Parsons, 1996: p. 17).

However, Parsons's solution to Hobbes's problem of social order is only a means for him to aim at an actual system theory. After explaining why the actors are not the problematic aspect in the explanation of the existence of social order, he was able to concentrate his analysis on the relationship between different systems and their functional importance for the whole. The discussion of Hobbes's problem and his system theory can be seen as different sides of the same coin. Both elements deal with the problem of social order, but the discussion of Hobbes's problem is the analysis of the forces dependent of the actors, whereas system theory is the analysis of the forces independent of the actors. Parsons's approach is consistent, because he was not only analyzing the social order problem in terms of an action theory but also in terms of a system theory. However, the result was that Parsons lost his action theory on the way to his system theory.

The basic difference between Parsons and Schutz is that they were focusing on different aspects of the methodological debate in economics. The German Historical School and Institutional Economics emphasized historical facts and a macro-perspective, whereas the Austrian School and Neoclassical Economics started with general statements about individual actors. Parsons was interested in the conflict between the society as a whole and the individual actors (cf. Beckert, 2006: p. 169), whereas Schutz dealt with the problem of historical facts and general concepts (Etzrodt, 2004: p. 99f.).

As a result, "Schutz approached the individual actor through the study of the structure of relevances in everyday life", whereas "Parsons accounted for the individual actor in terms of situational references within action systems” (Rehorick, 1980: p. 
351). Furthermore, Parsons assumed that the researcher as an observer knows more about the actor than the actor knows about himself/herself. He therefore emphasized the importance of the objective definition of the situation (Valone, 1980: p. 379). It is interesting that Parsons was actually closer to Max Weber than Schutz in relation to this issue. Weber echoed Simmel's contention that it is not necessary to be Caesar in order to understand Caesar, because the objective conditions in a given situation already explain a great deal about how the actors react (Cavalli, 1994: p. 231). Schutz on the other hand claimed that the observer only has a chance of interpreting another actor's behavior adequately if he/she is familiar with the observed actor's cultural background. In other words, in order to understand Caesar, we would need to be able to think as a Roman aristocrat would. This difference in the positions of Parsons and Schutz leads directly to the next issue: the Cartesian Dilemma.

\section{The Cartesian Dilemma}

The second methodological issue of the discussion between Schutz and Parsons was called by Grathoff the Cartesian Dilemma. This is the problem of intersubjectivity. How can we understand other people's behavior if their subjective motives and intentions exist only in their stream of consciousness, but never in ours (Grathoff, 1978b: p. xxf.)? And closely related to this question: What should be the starting point of a theory of understanding, the subjective stream of consciousness or the objective values, norms or symbols?

Alfred Schutz started as a methodological individualist from the subjective point of view of the actor. The search for a solution to the problem of how an intersubjective understanding can emerge out of a subjective mind became his main scientific focus. He saw a solution for this problem in the complementary concepts of increasing and decreasing abstraction for building general and specific types for interpretation (Etzrodt, 2001: p. 62f.; cf. Schutz, 1932: p. 206ff.; Prendergast, 1986: p. 18). In the first step an actor is building out of his whole experiences ${ }^{1}$ general types for situations, actors, and behavior by using the concept of increasing abstraction. He/she will for example formulate a general type of a man and a woman, old and young people, or even a more abstract type of a Japanese, based on his/her experiences with men and women and so on. These general types can be used now by the actor as a basis for the formulation of more specific types in the sense of the concept of decreasing abstraction. For example the actor, if he/she meets a close friend, will enrich the general type "man"/“woman" with the specific experiences he/she has had with his/her friend (for example, he/she knows that his/her friend is typically late). But the construction of types based on the subjective experience of an actor alone is not a solution for the intersubjectivity problem. Because if actors have totally different experiences in their lives, then the types constructed on this basis would also be different. And this would lead to misunderstandings. The solution lies in the fact that human beings are born into an existing society with a practiced culture (Schutz, 1943: p. 134; Schutz/Luckmann, 1979: p. 293). The types we are using are similar, because we have had our experiences in typi-

${ }^{1}$ In order to be more precise, the lived experiences (Erlebnisse) are not meaningful. They only become meaningful if they are "grasped reflectively" (Schutz, 1932: p. 72), "when the ego no longer immerses him/herself in the flow of duration” (Ho, 2008: p. 386; cf. Ferguson, 2006: p. 92f.). cal situations, with typical actors showing typical behavior (Schutz, 1953: p. 9; Schutz/Luckmann, 1979: pp. 151-293; Schutz/Gurwitsch, 1985: p. 279f.). And even the deviations from these types are after a while easy to recognize. Therefore we can understand other actors, because we use similar general types for unfamiliar and specific types for shared experiences of familiar situations, actors, and behavior. The existence of intersubjective shared types is therefore guaranteed, because of the social origin of our knowledge. But even this is not enough for an intersubjective understanding, because the actor must also expect in an interaction that his alter ego will see the situation in the same way as he sees it, independent of the biographical differences. This is guaranteed by the assumed reciprocity of the perspectives (Schutz, 1953: p. 7). Nevertheless, a perfect understanding is impossible, because two actors will never experience the same situation in the exact same way, therefore the mutual interpretation of each other's behavior will be necessarily deficient, even if they believe that they understood each other perfectly. The second problem for a perfect understanding is that some actors have had highly specific experiences in their life (for example, losing their parents as a child, or being raped), which are very difficult to explain if the alter ego lacks similar experiences. As a result of explaining highly specific experiences in general types, the underlying emotions often disappear. Therefore in Schutz's theory actors are real individuals with their own unique experiences, but they can understand each other most of the time to a sufficient degree by using the abstract level of general types as elements of a shared life world.

For Alfred Schutz a social scientist is confronted with a more complex problem ${ }^{2}$, because he uses specific concepts of a chosen action theory for the interpretation of observed human behavior. Generally these scientific concepts are more abstract than the general types used by normal people for interpretation, because they focus on a few of the theory-relevant aspects of that behavior. But Schutz insisted that these scientific concepts have to be related to the common-sense concepts of the lifeworld. For him every theory has to fulfill the postulate of adequacy. This postulate states that scientific terms must be reasonable and understandable by the observed people (Schutz, 1940: p. 59). This is the only guarantee of not losing the subjective point of view in a theory.

In contrast to Alfred Schutz, who saw in the problem of intersubjectivity the most important methodological problem in the social sciences, Talcott Parsons denied the existence of a gap in the knowledge between the scientific observer (or a normal observer) and the observed actor. He defined the view of the scientific observer as objective and the view of the actor as subjective.

By "objective" in this context will always be meant "from the point of view of scientific observer of action" and by "subjective", "from the point of view of the actor" (Parsons, 1937: p. 46).

In my opinion, Parsons's strategy to neglect the problem of intersubjectivity was a logical consequence of his voluntaristic theory and his solution to the social order problem (cf. Buxton, 1994: p. 272). His solution for the Hobbes-Parsons problem was based on the assumption that the actors internalize the normative values of the cultural system. But what Parsons un-

\footnotetext{
${ }^{2}$ However, this problem can be understood "as a variant on an endemically common-sense mode of apprehending the life world” (Kim/Berard, 2009: p. 265).
} 
derstood as "normative values" are not only value judgments, but also the meaning structure including the symbols of a society (Parsons, 1941a: p. 69; Rehorick, 1980: p. 354; cf. Cohen/ Hazelrigg/Pope, 1975: p. 233f.). Or to put it more exactly, meaning and symbols have a normative base for Parsons, and they direct the behavior of the actors.

Meaningful relations [...] condition action [...]. Their role is normative-they express relations between various elements and aspects of an ideal toward which action is oriented (Parsons, 1937: p. 483).

Norms, meaning, and symbols can be seen as a "cultural entity" (cf. Parsons, 1978: p. 116), which is internalized into the personality system as a whole. As a result of this, understanding becomes unproblematic, because every member of a society has internalized the same objective cultural entity (Etzrodt, 2001: p. 101). And of course, this also applies to the scientific observer. Therefore the observed actor and the scientific observer are using the same conceptual scheme for thinking, acting, and interpreting.

[The actors] act as well as think, in my opinion, in "terms of a conceptual scheme". [...] In principle the situation is not different for the scientific observer whose treatment of the subjective point of view must also in my opinion take place in terms of a conceptual scheme [...] (Parsons, 1978: p. 123) ${ }^{3}$.

Parsons does not mention in this statement that it must be necessarily the same conceptual scheme, but I think this is the only possibility to avoid the problem of intersubjective understanding. To deny my strict interpretation means to accept the intersubjectivity problem as a relevant problem, because if the scientific and common-sense concepts are not equivalent, then the researcher has to show how he wants to close the gap. However, the fact that Parsons excluded the intersubjectivity problem by choosing an objective starting point leads to two problems: one is a theoretical and the other a methodological problem. The theoretical problem is that Parsons not only excluded the problem of intersubjective understanding but also any form of individuality of the actor ${ }^{4}$. If an actor wants to be understood and to understand other people, he/she has to use the objective meaning structure based on the normative values, but if he/she uses these cultural entities, then he/she will be overdetermined by the values of the society. And there is no way out of this dilemma (cf. Etzrodt, 2008). Therefore Anthony Giddens (1976: p. 16) came to the conclusion that

[t]here is no action in Parsons's "action frame of reference", only behaviour which is propelled by need-dispositions or role expectations. The stage is set, but the actors only perform according to scripts which have already been written out for them.

The methodological problem which arises out of Parsons's position is indeed the problem discussed by Alfred Schutz. If a social scientist makes no distinction between the concepts which direct the behavior of the observed people and the scien-

\footnotetext{
${ }^{3}$ Wagner (1980: p. 399) pointed out correctly that this argumentation of Parsons is very close to Schutz's phenomenological thinking. However, in contrast to Parsons, Schutz consequently addressed the question of how individually constructed schemes of interpretation (or better, ideal-types) can produce an adequate understanding. It is therefore not the case as Wilson (2005) and Chew (2009) argued that the acceptance of shared schemes of interpretation (or ideal-types) rendered irrelevant the subjective point of view in both Parsons's and Schutz's approaches. Only in Parsons's theory is the subjective point of view of the actor neglected.

${ }^{4}$ At least Parsons left the question of how individuals can preserve their autonomy in such a normative system unanswered (Kim, 2003: p. 44).
}

tific concepts he/she uses, then he/she loses the chance to test his scientific concepts against the common-sense concepts. As a result of this, he/she can never be sure that the concepts which inform his/her analysis have anything to do with the subjective point of view of the actors. Only by safeguarding the subjective point of view can he/she "guarantee that social reality will not be replaced by a fictional nonexisting world constructed by some scientific observer" (Rehorick, 1980: p. 350; cf. Nasu, 1999: p. 71; Barber, 2004: p. 95) ${ }^{5}$. It becomes especially problematic if the theory is applied as a universal theory, because the scientific concepts could have a specific ethnocentric background, which leads to systematic misinterpretations in other cultures.

Professor Parsons has the right insight that a theory of action would be meaningless without the application of the subjective point of view. But he does not follow this principle to its roots. He replaces subjective events in the mind of the actor by a scheme of interpretation for such events [...]. [T] he only question Professor Parsons never asks is, what really does happen, in the mind of the actor from his subjective point of view. (Schutz, 1940: p. 36).

[T] he formation of the type, the choice of the typical event, and the elements considered as typical are all conceptual constructions which can be discussed objectively and which are open to criticism and verification. They are not formed by social scientists at random without check or restraint (Schutz, 1940: p. 59).

The contrasts between Schutz and Parsons can be seen as a consequence of the different theoretical aims. Schutz tried to solve the main methodological problem-the problem of intersubjective understanding - with an action theory based on the subjective point of view of the actor (Schutz, 1940: p. 36). Parsons, on the other hand, found a solution for the Hobbes-Parsons problem in the idea of the internalization of objective norms, which as a spin-off also solved the intersubjectivity problem, but with the cost of the exclusion of real individuality.

\section{The Kantian Problem}

The third and final methodological topic of the Schutz-Parsons Debate was called by Grathoff the Kantian Problem. The Kantian Problem is closely related to the Cartesian Dilemma. The Cartesian Dilemma describes the problem that for an intersubjective understanding, the concepts used by an observer for interpretation have to be related to the concepts used by the observed actor. On the other hand, the Kantian Problem deals with the relationship between concepts and "facts" (or sensory data). Facts are only perceptible and understandable if they are interpreted on the basis of common-sense knowledge or a scientific theory. But our schemes of interpretation in the sense of common-sense knowledge or a scientific theory will only lead to a correct interpretation if they provide an adequate pheno-

\footnotetext{
${ }^{5}$ This argument is also a serious challenge to Valone's (1980: p. 379f.; cf. Bernstein, 1976: p. 164; McLain, 1981: p. 110) statement that Parsons's standpoint is superior to Schutz's, because the researcher is able to recognize the actor's ideology and false consciousness, of which the actor himself/herself is unaware. The problem with this statement is of course that also the researcher could be a victim of his/her ideology, and as a result could see the world in an even more distorted way. Ideologies can only be revealed if it can be shown that ideological statements contradict reality. Therefore it is necessary to confront the researcher's interpretation of the situation with the actor's definition of the situation in order to reveal possible ideological distortions (Etzrodt, 2007: p. 70ff.).
} 
menon (or mental image) of the objects that have effected the sensory data. The Kantian Problem is therefore the dilemma that we cannot be sure about the correctness of our theories without a test against the facts, but that these facts do not exist without a theory, which again could be wrong.

Parsons dealt with the Kantian Problem in his methodological theory of analytical realism. Parsons claimed that 1) the objective world exists independent of the human mind, that 2) logically interrelated universal concepts (in the sense of a frame of reference) can correspond to the natural order of the objective world, and consequently that 3) the objective world can be analyzed, if a generalized scheme of interpretation is applied (Rehorick, 1980: p. 349; Münch, 1981: p. 727; Schmid, 1994: p. 280f.; cf. Parsons, 1938: p. 18), which 4) "must conform with the 'structural-functional' type” (Parsons, 1948: p. 158). This methodological standpoint was interpreted "as a derivative of Kant's epistemology”, although it has its roots in Whitehead's philosophy (Münch, 1981: p. 727) ${ }^{6}$. It seems that Parsons had accepted Kant's insight and assumed that the difference between his and Schutz's position in relation to the Kantian Problem lay in Schutz's denial of Kant's methodology.

The fundamental point here is that I defined a fact as a statement about one or more phenomena of the external world rather than as itself a phenomenon. Schutz takes issue with this and suggests that something like "experience" of phenomena is attainable without the mediation of what Henderson called a conceptual scheme, Kant the categories of the understanding (Parsons, 1978: p. 115f.)

But this is in my opinion clearly a misinterpretation of Alfred Schutz's position (cf. Wagner, 1980: p. 390ff.) ${ }^{7}$. Schutz agreed with the statement, that facts must be interpreted through a conceptual scheme to become understandable.

All our knowledge of the world, in common-sense as well as in scientific thinking, involves constructs, i.e., a set of abstractions, generalizations, formalizations, idealizations specific to the respective level of thought organization. Strictly speaking, there are no such things as facts, pure and simple. All facts are from the outset facts selected from a universal context by the activities of our mind. They are, therefore, always interpreted facts [...]. (Schutz, 1953: p. 3)

Ultimately, both agreed with the Kantian proposition. But the difference between Schutz's and Parsons's position had its origin in the incompatibility of the usage of the term "fact". Schutz was criticizing Parsons for using the term "fact" in the sense of an "empirically verifiable statement about phenomena

\footnotetext{
${ }^{6}$ I disagree here with Münch's interpretation that Parsons's methodology is a derivation of Kant's epistemology. Since Kant only provided a proof that there is a possibility of true theories and not a method of finding true theories nor of proposing a "true" theory, Parsons's statement that sociologists "must" apply a structural-functional theory stands in sharp contradiction to Kant's critical rationalism. Kant would have rejected Parsons's (1948: p. 159) belief that the existence and the characteristics of a social system have to be "assumed as a matter of fact". This is exactly the kind of belief - $a$ priori given and treated as truth-that Kant criticized (cf. Schmid, 1989: chapter 2; Savage, 1981: p. 83ff.).

${ }^{7}$ In order to be fair, Parsons's critique is justified if it is applied to Husserl's transcendental reduction. Husserl inverted the order of Kant's argument that a logical scheme is the foundation of experiences by stating that schemes of interpretation are themselves the result of experiences. However, Schutz's position is more complicated, since he applied only a mundane reduction. On the one hand, newborn members of a society have to construct their ideal-types based on their subjective experiences. But on the other hand they are born into a pre-existing society in which the actors use culturally specific ideal-types. The common-sense scheme of interpretation exists before the newborn member has his/her first experiences (cf. Ferguson, 2006: p. 91f.).
}

in terms of a conceptual scheme” (Schutz, 1940: p. 10, emphasis added). Instead of this, he insisted that facts, concepts, and statements about facts (by using signs) are, from a methodological point of view, three different elements.

First: facts and phenomena as they are given to the human mind. Secondly: interpretation of these facts and phenomena within the framework of a conceptual scheme. Thirdly: statements about the facts and their interpretation (Schutz, 1940: p. 10, emphases added).

Parsons defended his position, because for him "observed phenomena relevant to social science are treated as symbols with meanings” (Parsons, 1941a: p. 69). For him, scientific concepts were constructed on the basis of a language (related signs), and therefore also the experienced facts are necessarily statements about facts, because they only become facts in the moment they are interpreted through concepts (represented by signs) and stated.

We always observe, i.e. we experience, in terms of a conceptual scheme. Furthermore, precisely because and insofar as experience is conceptualized it is a matter of statements or propositions [...]. [T]o me, facts are not "described" but are "stated" (Parsons, 1941a: p. 68).

The problem of this argumentation is that as a result of the lack of distinction between facts and statements about facts, Parsons forewent the possibility of testing his theory against reality. Parsons's theory becomes tautological. First he formulated concepts in the form of a theory, then he interpreted societies with these concepts, and finally he made statements based on these concepts, which he again defined as "facts." Of course, there cannot be any contradiction in his theory.

\section{Summary of Schutz's and Parsons's Methodological Thinking}

Tables $\mathbf{1}$ and $\mathbf{2}$ are summaries of the methodological thinking of Alfred Schutz and Talcott Parsons. Each table is divided into the three methodological elements facts, concepts, and signs and into four levels of abstractness of facts. The level of abstractness depends on the question of how directly a fact can be experienced. The first level of abstractness contains facts that can be seen or touched. For example, fire is a fact belonging to this level. The natural sciences normally deal with these kinds of facts. These facts can be experienced even without knowing the concept behind the fact. We can experience the heat of a flame even if we do not understand the physical and chemical processes behind it. But of course, to understand why a flame produces heat, physical and chemical concepts are necessary.

At the second level, the facts cannot be seen or touched directly any more, but products of these facts can be seen or touched. For example, a stock corporation cannot be seen or touched, but it is possible to buy a product or to receive a letter from this corporation, which again can be seen or touched. In contrast to the first level, which is mainly the domain of the natural sciences, the facts on all the higher levels can only be experienced if the observer possesses a concept that can explain the fact. If a researcher has for example no concept of "father" in his/her mind and if he/she observes an adult man holding the hand of a child, then he/she will only recognize them as an adult man and a child, without experiencing the specific relationship between the two. At the higher levels, concepts are a necessary prerequisite for experiencing facts. This is the main difference between the natural and the social sciences (Natanson, 1962: p. xxxvf.). 


\section{ETZRODT}

Table 1.

Schutz's methodological thinking ${ }^{\mathrm{a}}$.

\begin{tabular}{|c|c|c|c|c|c|c|c|}
\hline & Facts “experienced” & $\Rightarrow$ & & Concepts "understood" & $\Rightarrow$ & & Signs “described” \\
\hline $\begin{array}{l}\mathrm{f}_{1}, \mathrm{f}_{1}\left(\mathrm{c}_{1}\right) \\
\text { or } \\
\mathrm{f}_{1}\left(\mathrm{c}_{1}^{*}\right)\end{array}$ & $\begin{array}{l}\text { "fire" } \\
\text { (I can feel the heat, without } \\
\text { knowing the concept fire.) }\end{array}$ & $\begin{array}{l}\Rightarrow \\
\text { or } \\
\Leftrightarrow\end{array}$ & $\begin{array}{l}\mathrm{c}_{1} \\
\text { 食 } \\
\mathrm{C}_{1}^{\circ}\end{array}$ & $\begin{array}{l}\text { The fire is an object of the physical } \\
\text { and the social world. }\end{array}$ & $\Rightarrow$ & $\mathrm{s}_{1}$ & $\begin{array}{l}\text { The "fire" is a meaningful object, } \\
\text { which produces heat. }\end{array}$ \\
\hline $\begin{array}{l}\mathrm{f}_{2}\left(\mathrm{c}_{2}\right) \\
\text { or } \\
\mathrm{f}_{2}\left(\mathrm{c}_{2}^{*}\right)\end{array}$ & $\begin{array}{l}\text { “father” or "mother's brother” (I } \\
\text { can count the interactions } \\
\text { between S and F or MB.) }\end{array}$ & $\Leftrightarrow$ & $\begin{array}{l}\mathrm{C}_{2} \\
\text { 企 } \\
\mathrm{C}_{2}^{*}\end{array}$ & $\begin{array}{l}\text { The father is a cultural concept as } \\
\text { social or biological father. }\end{array}$ & $\Rightarrow$ & $\mathrm{s}_{2}$ & $\begin{array}{l}\text { The "father" is a social construct that } \\
\text { serves a differrent purpose in differen } \\
\text { cultures. }\end{array}$ \\
\hline $\begin{array}{l}f_{3}\left(c_{3}\right) \\
\text { or } \\
f_{3}\left(c_{3}^{*}\right)\end{array}$ & $\begin{array}{l}\text { "GNP" } \\
\text { (I can measure the GNP.) }\end{array}$ & $\Leftrightarrow$ & $\begin{array}{l}\mathrm{C}_{3} \\
\text { 企 } \\
\mathrm{C}_{3}^{\circ}\end{array}$ & $\begin{array}{l}\text { The GNP is a cultural concept } \\
\text { dependent on what is counted. }\end{array}$ & $\Rightarrow$ & $\mathrm{s}_{3}$ & $\begin{array}{l}\text { The "GNP" is an indicator for } \\
\text { economic success. }\end{array}$ \\
\hline $\begin{array}{l}? \\
\mathrm{C}_{4}\left(\mathrm{C}_{4}^{*}\right)\end{array}$ & $\begin{array}{l}\text { "God” (I cannot see god, but I can } \\
\text { ask, what others think about god.) }\end{array}$ & $\Leftrightarrow$ & $\begin{array}{l}\mathrm{C}_{4} \\
\text { 食 } \\
\mathrm{C}_{4}^{\circ}\end{array}$ & $\begin{array}{l}\text { God as one of others or the only one } \\
\text { dependent on the religion. }\end{array}$ & $\Rightarrow$ & $\mathrm{S}_{4}$ & $\begin{array}{l}\text { "God” is a social construct that } \\
\text { explains our existence. }\end{array}$ \\
\hline
\end{tabular}

Note: a'Schutz's problem is the analysis of the relationship between the fact and the concept on the one side and between the common-sense concept and the scientific concept on the other.

Table 2.

Parsons's methodological thinking .

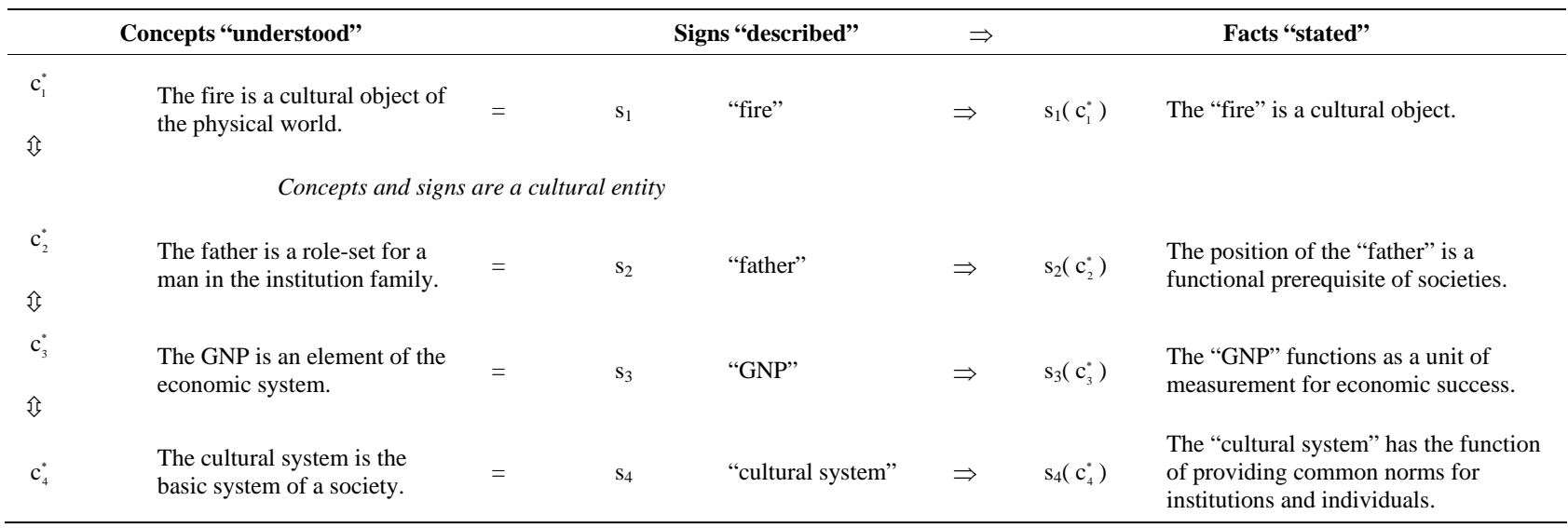

Note: a Parsons's problem is the analysis of the relationship between the concepts, including the relationship between concepts of different levels of abstractness (the system of concepts).

At the third level of abstraction, facts and their products cannot be seen or touched anymore, but they can be measured. An example at this level is the "gross national product". Nobody has ever seen or touched a GNP, but for economists it is one of the most important facts. What is counted (and therefore measured) depends of course on the scientific (economic) concept of the GNP. It is, for example, a result of the concept's definition, whether the offshore production of national companies is counted or not. However, without this concept, economic success could only be experienced after several years (for instance, it could be possible to see the differences of Japan's economic capabilities between the 1950's and 1980's, but not the differences between 1999 and 2000, because these differences are too small to be recognized without any statistical measurement).

The fourth level contains facts which cannot be seen, touched or measured. In other words, it is nearly impossible to experience these facts at this level of abstractness. Examples of such "facts" are the "cultural system" or "god." As a result of the impossibility of experiencing these "facts" directly, it is also impossible to verify or to falsify hypotheses about these "facts." But if you cannot prove the existence of a "fact," then it becomes a question of belief in the "fact."

Using these differentiations of facts, concepts, and signs on the one hand and four levels of abstractness of the facts on the other, it becomes possible to compare the methodological thinking of Alfred Schutz and Talcott Parsons. Both accept the point that facts, $f$, must be interpreted through concepts $f(c)$ or $f\left(c^{*}\right)$ to become observable (the " ${ }^{*}$ " indicates scientific concepts $)^{8}$. But the first striking difference between their positions is the definition of the "fact." For Parsons, facts are symbols with meanings, or to put it in the described terminology, Parsons defined facts in the social sciences as signs interpreted

\footnotetext{
${ }^{8}$ In the case of Schutz, one exception to this rule exists. Facts $\mathrm{f}_{1}$ on the first level of abstractness (like, for example, fire) do not necessarily require pre-given concepts in order to be experienced, because they can be experienced through immediate bodily contact. Srubar (2008: p. 46) called this an "asemiotic mechanism of constitution".
} 
through concepts $s\left(c^{*}\right)$. Therefore facts for him are not experienced but stated. In opposition to Parsons, Schutz made a clear distinction between facts and statements about facts (by using signs). He insisted on the difference between the written word "fire" on paper $s_{1}$ and fire as a physical process $f_{1}$. The question mark in Table 1 for the forth level of the facts indicates that Schutz never talked about "facts" $\mathrm{f}_{4}$ at this level of abstractness, and as such, it is my reconstruction of his possible standpoint in this question. Schutz said that in order to understand and explain facts, it is necessary to relate them to the categories of an action theory, but "facts" like the "cultural system" or "god" are not at all related to any human behavior (by definition of the concepts), therefore I would conclude that it is impossible to deal with these "facts" in an interpretative sociology in the Schutzian sense. But although it is impossible to deal with these "facts" $f_{4}$, it is not impossible to deal with the concepts $c_{4}$ which people use in their life-world. For example, it makes no sense to discuss the existence of "god" in the social sciences, but it can be very interesting to analyze the common-sense beliefs $c_{4}\left(c_{4}^{*}\right)$ about "god." And indeed it is not an implausible hypothesis that belief in a specific religion influences behavior. It is therefore possible to deal with common-sense concepts of god or the cultural system, but not with "god" or the "cultural system" as facts themselves. The difference in the positions of Schutz and Parsons is therefore that in Schutz's methodological position facts $f_{1}-f_{3}$ or common-sense concepts of "facts" $c_{4}$ dependent on the level of the facts' abstractness are analyzed, whereas Parsons's position deals with linguistic statements about facts $\mathrm{s}_{\mathrm{i}}$ independent of the level of abstractness.

The second difference between Schutz's and Parsons's methodology is the relationship between facts and concepts. In Parsons's position, signs (signifier) and concepts (signified) are a cultural entity, which everybody internalizes in the process of socialization. Therefore also statements about facts by using signs interpreted through concepts are necessarily equivalent to the concept itself: $s_{i}\left(c_{i}^{*}\right)=c_{i}^{*}$. For example, the sign "father" exists in every language in the world. The sign "father" can be interpreted through the concept father as a role-set for a man in the family-institution, in the sense of the head of the family (based on the experience of the researcher), and therefore he is responsible for his children. The existence of the sign "father" in every culture "proves" the important role of the father's position as a functional prerequisite for a society in general. The following statement will reveal the problems of this argumentation.

Parsons draws attention to what he regards as the four fundamental empirical clusterings of every society: kinship, social classes, territorially based organizations of force, and religious institutions and associations. His thesis here is that these structures are indispensable to any society and that their variation both historically and cross-culturally is severely limited [...]. The argument is tautological, resting on the assumptions and concepts of functionalism. He reflects on societies of the past and present, including one that professes to be fundamentally different, and all of which have kinship forms falling within what he defines as a "narrow sector". From this he infers the existence of certain functional imperatives-which, in turn, he employs to argue the necessity of the "narrow sector" [...]. This is speculation, not science, and may even be ideology. (Zeitlin, 1973: p. 26f.)

In the Schutzian position, the relationship between facts and concepts is based on a mutual dependency. Concepts are ne- cessary to understand and to experience the facts: $c_{i}^{*} \Rightarrow f_{i}\left(c_{i}^{*}\right)$. But on the other hand the researcher has to prove the usefulness of his or her concepts. This is possible by testing the concepts empirically against the facts and by developing new concepts out of the results of these tests: $f_{i}\left(c_{i}^{*}\right) \Rightarrow c_{i}^{* \prime} 9$. Schutz demanded that concepts be verified (Schutz, 1940: p. 60; Schutz, 1943: p. 147). I, however, prefer to use a falsification strategy instead of a verification strategy, because of Karl Popper's (1935: p. 6f.) argument that verification is logically impossible, although I am aware that Popper's position is also not without problems. But I am talking here about a theory-internal test and not about a test of two theories with different research strategies against each other. Therefore in my opinion it is possible to test $^{10}$ two concepts under a given perspective in a given research strategy against each other, and to falsify the concept which is less successful in explaining an experienced fact.

I will explain this method by using the above discussed example of the fact "father". A researcher could start with the concept of a father as a role-set for a man in the family-institution with responsibility for his children. He/she could operationalize the idea of responsibility through the number of interactions between the father and the children. And then he could test his hypothesis that this concept of a father is a functional prerequisite of societies against an alternative hypothesis that the concept of a mother is fundamental for societies, and that the man in the family is exchangeable. He could test these alternative hypotheses for white American middle-class families and for Khasi families (a matrilineal tribe in North-Eastern India). The researcher could compare the number of interactions, and I presume that he would get the result that in both societies the mother interacts very often with the children, but only in the white American middle-class family does the father play an important role, whereas in the Khasi society the mother's brother is more important than the father, in the sense of the number of interactions. Finally the researcher would falsify the hypothesis that the father is a functional prerequisite of societies, and he would accept the hypothesis that mothers are the heart of the family, whereas the man is exchangeable, as long as no other hypothesis fits better to the facts and as long as no other facts contradict this hypothesis. The mutual dependency between facts and concepts is easy to recognize in this example. Without the concepts of father, mother, and mother's brother, a researcher would count only interactions without identifying the relevant persons. And without the empirical test,

\footnotetext{
${ }^{9}$ Nasu (1999: p. 74; cf. Hama, 1999: p. 185) seems to imply that Schutz was not interested in the connection between facts and concepts: "As a phenomenologist, he [Schutz] follows the thesis of Husserl that " $[a] l l$ real unities are "unities of meaning." "This is the reason why Schutz 'does not have to do with the objects themselves; he is interested in their meaning, as it is constituted by the activities of our mind'" (Schutz, 1962: p. 115). I think that such an interpretation is incorrect. Schutz's statement-cited by Nasu-referred to the eidetical approach in phenomenology and not to an empirical investigation. And Schutz (1962: p. 113) made clear that such an eidetic approach does not exclude empirical investigations: "Phenomenological methods can of course be applied with the greatest success within the empirical sphere as well. But only by recourse to the eidetical sphere can the aprioristic character of phenomenology as a prima philosophia and even as a phenomenological psychology be assured." (Cf. also Nenon, 1999: pp. 182-185) Besides, Schutz's concepts of Wirken and Wirkwelt would make no sense at all if the material reality or the physical world were unrelated to the actor's experiences and concepts (cf. Yu, 1999: p. 162).

${ }^{10} \mathrm{I}$ am not talking here about a singular test but about a series of tests. The naive belief that a concept or a theory can be falsified as a result of one failed test is not compatible with Popper's critical rationalism, because it implies a blind trust in test results (Kageyama, 2003: p. 115).
} 
he would not recognize that the ethnocentric hypothesis of the important role of the father is universally simply wrong.

What separates the position of Schutz from Parsons's is that Schutz accepted not only specific methods in the social sciences but also the methods applied in the natural sciences as fundamental for the social sciences (Schutz, 1954: p. 258; Eberle, 1984: p. 107; see Jung, 1999: p. 100f. for a contradictary interpretation). The scientific concepts in the social sciences must not only survive the test against the facts (the Kantian Problem), they must also be related to the common-sense concepts of the actors (the Cartesian Dilemma), if the researcher really wants to understand and explain social facts (the Weberian Suggestion).

$[A]$ word on the problem of the methodological unity of the empirical sciences. It seems to me that the social scientist can agree with the statement that the principal differences between the social and the natural sciences must not be looked for in a different logic governing each branch of knowledge. But this does not involve the admittance that the social sciences have to abandon the particular devices they use for exploring social reality for the sake of an ideal unity of methods which is founded on the entirely unwarranted assumption that only methods used by the natural sciences, and especially by physics, are scientific ones (Schutz, 1954: p. 272).

On the other hand, Parsons's position is not only in contradiction to the specific (hermeneutic) methods in the social sciences as the discussion of the Cartesian Dilemma showed, but also in contradiction to the methods applied in the natural sciences, although the oft-cited analogies between the natural sciences and system theory in Parsons's work (e.g. Parsons, 1941b: p. 87). For example, Parsons criticized Herbert Spencer's proto-sociology for its "premature closure”. He regarded a theory as an open construct that should be modified whenever facts contradict theoretical expectations (Parsons, 1950: p. 6). However, this implies that theories are no longer falsifiable, because a theory is never abandoned as a result of a bad empirical performance. In other words, Parsons's methodology demands that theories should not preclude the appearance of any facts. This is like stating that tomorrow it will rain, not rain, or another unexpected fact will be observed. Of course, such a statement is true. But unfortunately, it is also useless as a scientific statement, because it has no empirical content. Obviously, Parsons was not aware of the fundamental discrepancies of his methodological proposal and the methodology applied in the natural sciences.

The third striking difference between Schutz's and Parsons's position is related to the Cartesian Dilemma. On the one hand, Schutz-in order to bridge the gap between common-sense and scientific constructs (Psathas, 1999: p. 47)—demanded that scientific concepts have to be understandable by the persons who are the objects of the observation. The scientific concepts $c_{i}^{*}$ are understandable for these persons if they are related to the common-sense concepts $c_{i}$ in their life-world. For Parsons on the other hand, the link between scientific concepts and common-sense concepts was not important for his scientific work. Parsons was interested in the relationship of scientific concepts from different levels (e.g. $c_{3}^{*} \Leftrightarrow c_{4}^{*}$ ). However, in contrast to Talcott Parsons, Alfred Schutz could avoid an ethnocentric position with his research strategy. For example, a researcher who uses a Schutzian strategy would recognize that the Khasi possess two different concepts of a father in their life-world. One is the "father" as a "biological father" and the other is the "mother's brother" as a "social father". In white
American middle-class families the "father", in contrast to this, is typically both. This example shows that Parsons's hypothesis of the important role of the "father" in the family is probably not so wrong if the ethnocentric concept of the "biological father" is replaced with the concept of the "social father". Some problems can be avoided if the scientific concepts are tested against the common-sense concepts in different cultural groups, before they are tested against the facts.

In my opinion it is obvious that Parsons's methodological position is oversimplified and deficient. This kind of methodological thinking produces three main problems:

1) The usage of a statement about facts as the facts leads to a linguistic analysis, but not to an analysis of social facts.

2) The declaration of facts/signs and concepts as cultural entities excludes any possibility of an empirical test of the theory, especially if the concepts are constructed arbitrarily (MiklHorke, 2001: p. 231).

3) The neglect of the difference between common-sense and scientific concepts leads necessarily to an ethnocentric point of view, if the theory is constructed as a universal theory, and in every case to a naïve scientific position (cf. Natanson, 1978: p. xi; Nasu, 1999: p. 71).

Nevertheless, Parsons's methodological position is not unreasonable. Of course, his position is implausible for the first three levels of abstractness of facts, and therefore unacceptable. But it was not Parsons's aim to talk about these levels. He wanted to analyze the highly abstract social facts, and for this analysis Schutz's methodological implications are not very useful, because they exclude these "facts" from the research program. And if a "cultural system" were really to exist with its own dynamic independent of the actors' behavior, then it would be a serious mistake not to deal with such a topic in sociology. Parsons's position on this point is consistent: constructing the concepts first and then analyzing societies based on this conceptual scheme.

However, I have two objections to such a position. The first is that it is not possible to test the concepts against the facts, because of their high degree of abstractness. Out of this follows that theories dealing with the system level cannot be evaluated. Nobody can say that one theory is better than any other theory. And the second objection is that to assume the independence of a "cultural system" from human actions sounds for me like an excuse for avoiding a careful and detailed study of mutual dependencies between culture and human behavior.

[T] he crucial characteristic of structural-functional theory is its use of the concept system without a complete knowledge of the laws which determine processes within the system (Parsons, 1951: p. 483, emphasis in the original).

\section{REFERENCES}

Barber, M. D. (2004). The participating citizen: A biography of Alfred Schutz. Albany, NY: SUNY Press.

Beckert, J. (2006). Interpenetration versus embeddedness: The premature dismissal of Talcott Parsons in the new economic sociology. In L. S. Moss, \& A. Savchenko (Eds.), Talcott Parsons: Economic sociologist of the 20th century (pp. 161-188). Malden: Blackwell.

Bernstein, R. J. (1976). The restructuring of social and political theory. Oxford: Blackwell.

Buxton, W. J. (1994). Academic dispute or clash of commitments? The Schutz-Parsons exchange. Human Studies, 17, 267-275. doi:10.1007/BF01323605

Camic, C. (1991). Introduction. In T. Parsons (Ed.), The early essays 
(pp. ix-lxix). Chicago/London: University of Chicago Press.

Cavalli, A. (1994). Max weber und Georg Simmel: Sind die divergenzen wirklich so groß (Max weber and Georg Simmel: Are the divergences really that big). In G. Wagner, \& H. Zipprian (Eds.), Max webers wissenschaftslehre (Max weber's philosophy of science, pp. 224-238). Frankfurt: Suhrkamp.

Chew, M. M. (2009). The theoretical quandry of subjectivity: An intellectual historical note on the action theories of Talcott Parsons and Alfred Schutz. Review of European Studies, 1, 23-34.

Cohen, J., Hazelrigg, L. E., \& Pope, W. (1975). De-Parsonizing weber: A critique of Parsons' interpretation of weber's sociology. American Sociological Review, 40, 229-241. doi:10.2307/2094347

Coser, L. A. (1979). A dialogue of the deaf. Contemporary Sociology, 8, 680-682. doi:10.2307/2065416

Eberle, T. S. (1984). Constitution of meaning in everyday life and science: The contribution of phenomenology to the methodology of the social sciences. Bern/Stuttgart: Haupt.

Etzrodt, C. (2001). Human behaviour: A synthesis of microeconomic and microsociological theories. Konstanz: Universitätsverlag Konstanz.

Etzrodt, C. (2004). Why actors don't choose. A comparison of Talcott Parsons's and Alfred Schutz's action theories in relation to economics. The Annual Review of Sociology and Social Theory, 3, 98-115.

Etzrodt, C. (2007). How can Alfred Schutz's phenomenology increase the fruitfulness of Popper's methodological individualism? Ritsumeikan Social Science Review, 43, 59-75.

http://www.ritsu mei.ac.jp/acd/cg/ss/sansharonshu/431pdf/03-04.pdf

Etzrodt, C. (2008). The foundation of an interpretative sociology: A critical review of the attempts of George H. Mead and Alfred Schutz. Human Studies, 31, 157-177. doi:10.1007/s10746-008-9082-0

Ferguson, H. (2006). Phenomenological sociology: Experience \& insight in modern society. London: Sage.

Fusfeld, D. R. (1987). Methodenstreit. In J. Eatwell, M. Milgate, \& P. Newman (Eds.), The new Palgrave: A dictionary of economics (pp. 454-455). London/Basingstoke: Macmillan.

Giddens, A. (1976). New rules of sociological method. London: Hutchinson.

Goode, W. J. (1960). Norm commitment and conformity to role-status obligations. American Journal of Sociology, 66, 246-258. doi:10.1086/222876

Grathoff, R. H. (1978a). Alfred Schütz. In D. Käsler (Ed.), Classics of sociological thought (pp. 388-416). München: Beck.

Grathoff, R. H. (1978b). Introduction. In A. Schutz, \& T. Parsons (Ed.), The theory of social action (pp. xvii-xxvi). Bloomington: Indiana University Press.

Hama, H. (1999). Ethnomethodology and the Rashomon problem. Human Studies, 22, 183-192. doi:10.1023/A:1005436400730

Ho, W.-C. (2008). Understanding the subjective point of view: Methodological implications of the Schutz-Parsons debate. Human Studies, 31, 383-397. doi:10.1007/s10746-008-9100-2

Jung, H. Y. (1999). Reading Natanson reading Schutz. In L. Embree (Ed.), Schutzian social science (pp. 87-113). Dordrecht: Kluwer. doi:10.1007/978-94-017-2944-4_5

Kageyama, Y. (2003). Openness to the unknown: The role of falsifiability in search of better knowledge. Philosophy of the Social Sciences, 33, 100-121. doi:10.1177/0048393102250307

Khairy, M. (1986). The search for a phenomenologically grounded theory of action: A critique of Schutz. Arab Journal of the Social Sciences, 1, 130-136.

Kim, K.-K. (2003). Order and agency in modernity: Talcott Parsons, Erving Goffman, and Harold Garfinkel. Albany: SUNY Press.

Kim, K.-K., \& Berard, T. (2009). Typification in society and social science: The continuing relevance of Schutz's social phenomenology. Human Studies, 32, 263-289. doi:10.1007/s10746-009-9120-6

McLain, R. (1981). The postulate of adequacy: Phenomenological sociology and the paradox of science and sociality. Human Studies, 4, 105-130. doi:10.1007/BF02127452

Mikl-Horke, G. (2001). Sociology. München: Oldenbourg.

Münch, R. (1981). Talcott Parsons and the theory of action: The structure of the Kantian core. American Journal of Sociology, 86, 709-739. doi:10.1086/227314
Nasu, H. (1999). Alfred Schutz's conception of multiple realities sociologically interpreted. In L. Embree (Ed.), Schutzian social science (pp. 69-85). Dordrecht: Kluwer. doi:10.1007/978-94-017-2944-4_4

Natanson, M. (1962). Introduction. In A. Schutz (Ed.), Collected papers (pp. xxv-xlvii). Den Haag: Nijhoff.

Natanson, M. (1978). Forword. In A. Schutz, \& T. Parsons (Eds.), The theory of social action (pp. ix-xvi). Bloomington: Indiana University Press.

Nenon, T. (1999). The phenomenological foundation of the social sciences. In L. Embree (Ed.), Schutzian social science (pp. 173-186). Dordrecht: Kluwer. doi:10.1007/978-94-017-2944-4 9

Parsons, T. (1937). The structure of social action. New York: McGrawHill.

Parsons, T. (1938). The role of theory in social research. American Sociological Review, 3, 13-20. doi:10.2307/2083507

Parsons, T. (1941a). Letter to Alfred Schutz from January 16, 1941. In A. Schutz, \& T. Parsons (Eds.), The theory of social action (pp. 6370). Bloomington, IN: Indiana University Press.

Parsons, T. (1941b). Letter to Alfred Schutz from February 2, 1941. In A. Schutz, \& T. Parsons (Eds.), The theory of social action (pp. 7993). Bloomington, IN: Indiana University Press.

Parsons, T. (1948). The position of sociological theory. American Sociological Review, 13, 156-164. doi:10.2307/2087030

Parsons, T. (1950). The prospects of sociological theory. American Sociological Review, 15, 3-16. doi:10.2307/2086393

Parsons, T. (1951). The social system. Glencoe: Free Press.

Parsons, T. (1978). A 1974 retrospective perspective. In A. Schutz, \& T. Parsons (Eds.), The theory of social action (pp. 115-124). Bloomington, IN: Indiana University Press.

Parsons, T. (1996). The theory of human behavior in its individual and social aspects. American Sociologist, 27, 13-23. doi:10.1007/BF02692048

Popper, K. R. (1935). The logic of scientific discovery. Wien: Springer.

Psathas, G. (1999). On the study of human action: Schutz and Garfinkel on social science. In L. Embree (Ed.), Schutzian social science (pp. 47-68). Dordrecht: Kluwer. doi:10.1007/978-94-017-2944-4_3

Prendergast, C. (1986). Alfred Schutz and the Austrian school of economics. American Journal of Sociology, 92, 1-26. doi:10.1086/228461

Rehorick, D. A. (1980). Schutz and Parsns: Debate or dialogue? Human Studies, 3, 347-355. doi:10.1007/BF02331820

Savage, S. P. (1981). The theories of Talcott Parsons: The social relations of action. London/Basingstoke: Macmillan.

Schmid, M. (1989). Social theory and social system. München: Forschungsberichte der Universität der Bundeswehr.

Schmid, M. (1994). Analytical theory and the method of the cultural sciences: Talcott Parsons's interpretation of Max weber's philosophy of science. In G. Wagner, \& H. Zipprian (Eds.), Max Weber's philosophy of science (pp. 278-309). Frankfurt: Suhrkamp.

Schutz, A. (1932). The phenomenology of the social world. Wien: Springer. doi:10.1007/978-3-7091-3108-4

Schutz, A. (1940). Parsons' theory of social action: A critical review. In A. Schutz, \& T. Parsons (Eds.), The theory of social action (pp. 8-60). Bloomington, IN: Indiana University Press.

Schutz, A. (1943). The problem of rationality in the social world. Economica, 10, 130-149. doi:10.2307/2549460

Schutz, A. (1953). Common-sense and scientific interpretation of human action. Philosophy and Phenomenological Research, 14, 1-37. doi:10.2307/2104013

Schutz, A. (1954). Concept and theory formation in the social sciences. Journal of Philosophy, 51, 257-273. doi:10.2307/2021812

Schutz, A. (1955). Letter to Adolph Lowe from 7 december 1955. Baden-Württemberg: Universität Konstanz.

Schutz, A. (1962). Some leading concepts of phenomenology. In A. Schutz (Ed.), Collected papers I: The problem of social reality (pp. 99-117). The Hague: Nijhoff. doi:10.1007/978-94-010-2851-6 4

Schutz, A., \& Gurwitsch, A. (1985). Briefwechsel 1939-1959 (Philosophers in exile: The correspondence of Alfred Schutz and Aron Gurwitsch). München: Wilhelm Fink.

Schutz, A., \& Luckmann, T. (1979). Structures of the life-world. Frankfurt: Suhrkamp. 


\section{ETZRODT}

Skidmore, W. (1975). Theoretical thinking in sociology. Cambridge: Cambridge University Press.

Srubar, I. (2008). The pragmatic life-world theory. In Jürgen Raab, et al. (Eds.), Phenomenology and sociology (pp. 41-51). Wiesbaden: VS Verlag für Sozialwissenschasften.

Tibbetts, P. (1980). The issue of human subjectivity in sociological explanation: The Schutz-Parsons controversy. Human Studies, 3, 357366. doi:10.1007/BF02331821

Turner, B. S. (1994). Life philosophy and action theory: How the relationship between Talcott Parsons and Max Weber contributed to the development of sociology. In G. Wagner, \& H. Zipprian (Eds.), Max Weber's philosophy of science (pp. 310-331). Frankfurt: Suhrkamp.

Valone, J. J. (1980). Parsons' contributions to sociological theory: Reflections on the Schutz-Parsons correspondence. Human Studies, 3, 375-386. doi:10.1007/BF02331823
Wagner, H. R. (1980). Reflections on Parsons' “1974 retrospective perspective” on Alfred Schutz. Human Studies, 3, 387-402. doi:10.1007/BF02331824

Wilson, T. P. (2005). The problem of subjectivity in Schutz and Parsons. In M. Endress, G. Psathas, \& H. Nasu (Eds.), Explorations of the life-world (pp. 19-49). Dordrecht: Springer. doi:10.1007/1-4020-3220-X 2

Yu, C.-C. (1999). Schutz on lifeworld and cultural difference. In L. Embree (Ed.), Schutzian social science (pp. 159-172). Dordrecht: Kluwer. doi:10.1007/978-94-017-2944-4_8

Zafirovski, M. (2006). Parsonian economic sociology: Bridges to contemporary economics. In L. S. Moss, \& A. Savchenko (Eds.), Talcott Parsons: Economic sociologist of the 20th century (pp. 75-107). Malden: Blackwell.

Zeitlin, I. M. (1973). Rethinking sociology. New York: Meredith. 